\title{
Feeding Bottles Usage and the Prevalence of Childhood Allergy and Asthma
}

\author{
Nai-Yun Hsu, ${ }^{1}$ Pei-Chih Wu, ${ }^{1,2}$ Carl-Gustaf Bornehag, ${ }^{3}$ Jan Sundell, ${ }^{4}$ and Huey-Jen Su${ }^{1}$ \\ ${ }^{1}$ Department of Environmental and Occupational Health, College of Medicine, National Cheng Kung University, Tainan 70403, Taiwan \\ ${ }^{2}$ Department of Occupational Safety and Health, Chang Jung Christian University, Tainan 71101, Taiwan \\ ${ }^{3}$ Public Health Sciences, Karlstad University, 65188 Karlstad, Sweden \\ ${ }^{4}$ International Centre for Indoor Environment and Energy, Technical University of Denmark, 2800 Lyngby, Denmark \\ Correspondence should be addressed to Huey-Jen Su, hjsu@mail.ncku.edu.tw
}

Received 31 July 2011; Revised 18 November 2011; Accepted 24 November 2011

Academic Editor: Kuender D Yang

Copyright (๑) 2012 Nai-Yun Hsu et al. This is an open access article distributed under the Creative Commons Attribution License, which permits unrestricted use, distribution, and reproduction in any medium, provided the original work is properly cited.

This study aimed to examine the association between the length of use of feeding bottles or pacifiers during childhood and the prevalence of respiratory and allergic morbidities. A large-scale questionnaire survey was performed in day care centers and kindergartens (with children's ages ranging from 2 to 7 years) in southern Taiwan, and a total of 14,862 questionnaires completed by parents were finally recruited for data analysis. Effects of using feeding bottles on children's wheezing/asthma (adjusted OR: 1.05, 95\% CI 1.00-1.09), allergic rhinitis (adjusted OR: 1.04, 95\% CI 1.00-1.08), and eczema (adjusted OR: 1.07, 95\% CI 1.011.2) were found. Moreover, significant dose-dependent relationships were further established after an adjustment for confounders was performed that included children's ages, gender, gestational age, birth weight, length of breastfeeding, the age when first given infant formula or complementary foods, family history, parental educational levels, and smoking status, as well as the problem of indoor water damage. This study was the first to reveal the potential risk of using plastic consumer products such as feeding bottles on the reported health status of preschool children in Asian countries.

\section{Introduction}

Because of the multifactorial nature of pathogenesis, it is much clearer now that the rising prevalence and morbidity of childhood asthma and allergic diseases cannot be explained only by genetics and allergen exposure. Several chemicals from many common consumer products have been shown to have toxicity in animal studies and have also been suggested to have an impact on human health. For example, bisphenol A (BPA) is used to manufacture polycarbonate plastic and epoxy resins, which are used in a large number of products found indoors, such as epoxy, building components, and electronic equipment as well as protective coatings on food containers and baby bottles. Toxicological studies of animals have suggested that exposure to BPA is associated with morphologic, functional, and behavioural anomalies related to reproduction. Phthalate esters are stabilizers and plasticizers in commonly used consumer products [1] such as personal care products, food packaging, medical equipment, toys, and building materials. Experimental studies during the past decade have proposed their role as an adjuvant on $\mathrm{T}_{\mathrm{H}} 2$ differentiation or as having an association with the early phases of inflammatory response $[2,3]$.

We are commonly exposed to various chemicals with potential health concerns in our daily lives through the use of consumer products; however, there have been no studies attempting to verify whether the use of these kinds of products is associated with health status, especially in the case of the most susceptible group, young children. The current analysis was aimed at an examination of the association between the length of use of pacifiers or feeding bottles during childhood and the prevalence of respiratory and allergic disease/symptoms in a Taiwanese population.

\section{Materials and Methods}

2.1. Study Subjects. In 2005 and 2006, randomly selected kindergartens $(n=201)$ and day care centres $(n=259)$ 
in the Greater Tainan metropolitan area of southern Taiwan were asked through telephone interviews to participate in a questionnaire survey aimed at identifying the relationship between indoor environmental quality in the home to children's health. An average of $73 \%$ of the successfully contacted schools $(n=335)$ agreed to participate and to help send a questionnaire to the parents of children between the ages of 2 and 6 who attended their schools. A total of 14,862 questionnaires were returned with a $68 \%$ response rate of questionnaires sent to the 355 kindergartens and day care centres. The study was approved by the Human Experiment and Ethics Committee at National Cheng Kung University Hospital in Tainan, Taiwan.

2.2. Questionnaire. Questions for assessment of the children's asthma and allergy were adopted from the International Study of Asthma and Allergies in Childhood (ISAAC) protocol [4], including the following questions.

Core question for wheezing and asthma.

(i) Has your child ever had wheezing or whistling in the chest at any time in the past?

(ii) In the last 12 months, has your child had a dry cough at night for more than two weeks, apart from a cough associated with a cold or chest infection?

(iii) Has your child been diagnosed with asthma by a doctor?

Core question for allergic rhinitis.

(i) In the past 12 months, has your child had a problem with sneezing, or a runny, or a blocked nose when he/she DID NOT have a cold or the flu?

(ii) Has your child been diagnosed with hay fever or allergic rhinitis by a doctor?

Core question for eczema.

(i) Has your child ever had an itchy rash (eczema), which was coming and going for the last 6 months?

For the environmental condition component used on the questionnaire for this study, questions that were identical to the worldwide Dampness in Buildings and Health (DBH) study [5] were adopted. Questions regard to the length of use of pacifiers or feeding bottles in the survey were as follows.

(i) Did your child use a pacifier? If yes, at what age did your child stop using it?

(ii) Did your child use a feeding bottle? If yes, at what age did your child stop using feeding bottles?

There were eight options for answering either question, including "(1) never used, (2) stopped use before 1 year old, (3) stopped use before 2 years old, (4) stopped use before 3 years old, (5) stopped use before 4 years old, (6) stopped use before 5 years old, (7) stopped use before 6 years old, and (8) is still using."
2.3. Data Analysis. Differences in the percentages between any of the groups shown in Table 2 were calculated using a chi-square, while the $P$ value for trends was applied using a chi-square for the trend test (ordinary by ordinary) for ordinal data. Multivariable logistic regression was applied to examine the effect after adjusting for potential confounders. All statistical analysis was performed with the SPSS, version 17 (Chicago, IL, USA).

\section{Results}

Questionnaires were mostly filled out by mothers $(62.3 \%)$. Table 1 presents the characteristics of 14,862 children, including their ages, gender, gestational age, birth weight, length of being breastfed, the age first given infant formula or complementary foods, family history, parental educational levels, and smoking status. Moreover, a high prevalence of reported water damage in the home $(35.7 \%)$ was shown in southern Taiwan.

The lifetime prevalence of parental reporting of wheezing/asthma, allergic rhinitis, and eczema among preschool children is tabulated in Table 2 . The average prevalence of doctor-diagnosed asthma, doctor-diagnosed allergic rhinitis and the reporting of eczema symptoms during the 6 months prior to this study among preschool children in Taiwan was $9.3 \%, 19.3 \%$, and $17.6 \%$, respectively. More than half of the children studied $(50.8 \%)$ had rhinitis symptoms, including sneezing or a runny or blocked nose when they were absent resulting from having had a cold or a flu in the previous 12 months. The highest rate of diagnosed asthma was found at the age of 5 years old, at 10.2\%. Moreover, it was apparent that the prevalence of allergic rhinitis and reported symptoms was increasing along with the age of children, whereas an inverse situation was found for eczema. As to the morbidities of wheezing/asthma and rhinitis, children with any one of related symptoms or diseases were recognized as cases. Overall, there were $34.9 \%$ and $53.6 \%$ of preschool children with reported morbidities of wheezing/asthma and allergic rhinitis, respectively, in Taiwan.

With regard to clinical data, physician-diagnosed health statuses of young children, especially in the case of asthma, were not stable and permanent until the age of 3 years. The current analysis therefore excluded subjects who were younger than 3 years old ( $n=489$, Table 1 ) and those missing age information ( $n=1700$, Table 1$)$. The length of using pacifiers or feeding bottles among the study children was stratified into a quartile range as shown in Table 3. A total of $24.3 \%$ children never had used feeding bottles or had used them until they were 2 years old; $25.3 \%$ children had stopped use between 2 and 3 years old; $24.2 \%$ children had stopped use between 3 and 5 years old; the remaining $26.2 \%$ of the children had used these items until the time of this investigation. Results revealed that the prevalence rates of wheezing/asthma, allergic rhinitis, and eczema in the four groups were increasing significantly $(P$ value for trend $<0.05)$, with higher quartiles representing a longer length of using feeding bottles among the children who were subjects in this study. The only statistically significant trend between outcomes and 
TABle 1: Characteristics of study children.

\begin{tabular}{|c|c|c|}
\hline & $n(\%)$ & $n(\%)$ of missing data* \\
\hline Questionnaire filled out by & & $1,030(6.9)$ \\
\hline Both father and mother & $3,022(21.8)$ & \\
\hline Mother only & $8,619(62.3)$ & \\
\hline Father only & $1,738(12.6)$ & \\
\hline Grandparents & $216(1.6)$ & \\
\hline Others & $237(1.7)$ & \\
\hline Age & & $1,700(11.4)$ \\
\hline Less than 3 years old & $489(3.7)$ & \\
\hline 3 years old & $1,631(12.4)$ & \\
\hline 4 years old & $3,740(28.4)$ & \\
\hline 5 years old & $5,021(38.1)$ & \\
\hline $6 \sim 7$ years old & $2,281(17.4)$ & \\
\hline Gender & & $2,278(15.3)$ \\
\hline Female & $6,101(48.5)$ & \\
\hline Male & $6,483(51.5)$ & \\
\hline Gestational age & & $521(3.5)$ \\
\hline Before week 32 & $205(1.4)$ & \\
\hline In week 32-36 & $2,178(15.2)$ & \\
\hline In week $37-42$ & $10,731(74.8)$ & \\
\hline In week 43 or later & $745(5.2)$ & \\
\hline Unknown & $482(3.4)$ & \\
\hline Birth weight & & $230(1.5)$ \\
\hline Less than 2500 grams & $932(6.4)$ & \\
\hline $2500-4200$ grams & $13,376(91.4)$ & \\
\hline More than 4200 grams & $180(1.2)$ & \\
\hline Unknown & $144(1)$ & \\
\hline Breastfed totally or partly until & & $279(1.9)$ \\
\hline Never & $5,630(38.6)$ & \\
\hline Younger than 3 months & $6,087(41.7)$ & \\
\hline $3-6$ months & $1,371(9.4)$ & \\
\hline Older than 6 months & $1,495(10.3)$ & \\
\hline The age first given infant formula & & $969(6.5)$ \\
\hline Never & $248(1.8)$ & \\
\hline Younger than 3 months & $9,739(70.1)$ & \\
\hline 3-6 months & $2,568(18.5)$ & \\
\hline Older than 6 months & $1,338(9.6)$ & \\
\hline The age first introducing complementary foods & & $590(4)$ \\
\hline Never & $111(0.8)$ & \\
\hline Younger than 3 months & $220(1.5)$ & \\
\hline 3-6 months & $5,761(40.4)$ & \\
\hline Older than 6 months & $8,180(57.3)$ & \\
\hline Ever had allergic symptoms to foods & & $449(3)$ \\
\hline Unknown & $1,022(7.1)$ & \\
\hline Never & $11,947(82.9)$ & \\
\hline Yes, ever had allergic reaction to & $1,444(10.0)$ & \\
\hline seafood & $768(53.1)$ & \\
\hline milk or dairy products & $269(18.4)$ & \\
\hline
\end{tabular}


TABLe 1: Continued.

\begin{tabular}{|c|c|c|}
\hline & $n(\%)$ & $n(\%)$ of missing data* \\
\hline eggs & $233(16.1)$ & \\
\hline peanuts & $136(9.4)$ & \\
\hline fish & $124(8.6)$ & \\
\hline fruit & $101(7.0)$ & \\
\hline soya, peas, beans & $48(3.3)$ & \\
\hline vegetables & $44(3.1)$ & \\
\hline nuts, almond & $43(3)$ & \\
\hline flour & $34(2.4)$ & \\
\hline others & $376(26.1)$ & \\
\hline Family history & & $424(2.9)$ \\
\hline Paternal asthma & $310(2.1)$ & \\
\hline Paternal allergic rhinitis or eczema & $2,709(18.8)$ & \\
\hline Maternal asthma & $408(2.8)$ & \\
\hline Maternal allergic rhinitis or eczema & $2,733(18.9)$ & \\
\hline Sibling with asthma & $643(4.4)$ & \\
\hline Sibling with allergic rhinitis or eczema & $2,361(16.4)$ & \\
\hline Paternal educational levels & & $336(2.3)$ \\
\hline Junior and junior high school & $2,348(16.1)$ & \\
\hline Senior high school & $5,943(40.9)$ & \\
\hline Undergraduate degree & $5,216(35.9)$ & \\
\hline Graduate degree & $1,019(7)$ & \\
\hline Maternal educational levels & & $369(2.5)$ \\
\hline Lower than junior high school & $2,117(14.6)$ & \\
\hline Senior high school & $6,510(44.9)$ & \\
\hline Undergraduate degree & $5,476(37.8)$ & \\
\hline Graduate degree & $390(2.7)$ & \\
\hline Parents smoked during the child's first year of life & & $627(4.9)$ \\
\hline Either father or mother smoked & $6,303(49.7)$ & \\
\hline Indoor problems with water damage & & $215(1.7)$ \\
\hline In any room of the home & $3,205(35.7)$ & \\
\hline
\end{tabular}

* The percentage of missing data among 14862 subjects.

TABLe 2: Prevalence of diseases or symptoms among study children.

\begin{tabular}{|c|c|c|c|c|c|c|c|}
\hline & \multirow{2}{*}{ Total population, $\%(n)$} & \multicolumn{6}{|c|}{ Stratified by the age of child while questionnaire survey, $\%(n)$} \\
\hline & & $\begin{array}{c}\text { Less than } 3 \\
\text { years old }\end{array}$ & 3 years old & 4 years old & 5 years old & $\begin{array}{c}6 \sim 7 \\
\text { years old }\end{array}$ & $P$ value* \\
\hline \multicolumn{8}{|l|}{ Wheezing/asthma } \\
\hline Wheezing ever & $28.6(4090)$ & $33.9(161)$ & $31.8(507)$ & $28.3(1020)$ & $27.6(1325)$ & $28.3(618)$ & 0.002 \\
\hline Cough at night last 12 months & $11.2(1611)$ & $11.3(54)$ & $12.5(198)$ & $11.1(404)$ & $10.7(518)$ & $10.5(232)$ & 0.326 \\
\hline Doctor-diagnosed asthma & $9.3(1176)$ & $6.2(27)$ & $8.6(120)$ & $8.7(282)$ & $10.2(437)$ & $9.6(184)$ & 0.021 \\
\hline Any one of the abovementioned & $34.9(5146)$ & $39.0(190)$ & $38.3(623)$ & $34.5(1283)$ & $33.8(1685)$ & $33.9(766)$ & 0.002 \\
\hline \multicolumn{8}{|l|}{ Allergic rhinitis } \\
\hline Rhinitis last 12 months & $50.8(7301)$ & $44.2(212)$ & $49.5(786)$ & $49.1(1778)$ & $51.7(2517)$ & $53.9(1187)$ & $<0.001$ \\
\hline Doctor-diagnosed rhinitis & $19.3(2791)$ & $12.6(60)$ & $16.6(265)$ & $19.6(716)$ & $20.3(992)$ & $21.2(470)$ & $<0.001$ \\
\hline Any one of the abovementioned & $53.6(7906)$ & $46.9(229)$ & $51.9(843)$ & $52.6(1957)$ & $54.4(2714)$ & $56.7(1280)$ & $<0.001$ \\
\hline \multicolumn{8}{|l|}{ Eczema } \\
\hline Eczema during last 6 months & $17.6(2539)$ & $29.2(140)$ & $19.9(318)$ & $17.4(635)$ & $16.4(798)$ & $16.3(361)$ & $<0.001$ \\
\hline
\end{tabular}

${ }^{*} P$ values were calculated by Pearson Chi-Square to compare the difference of percentages among five age groups. 


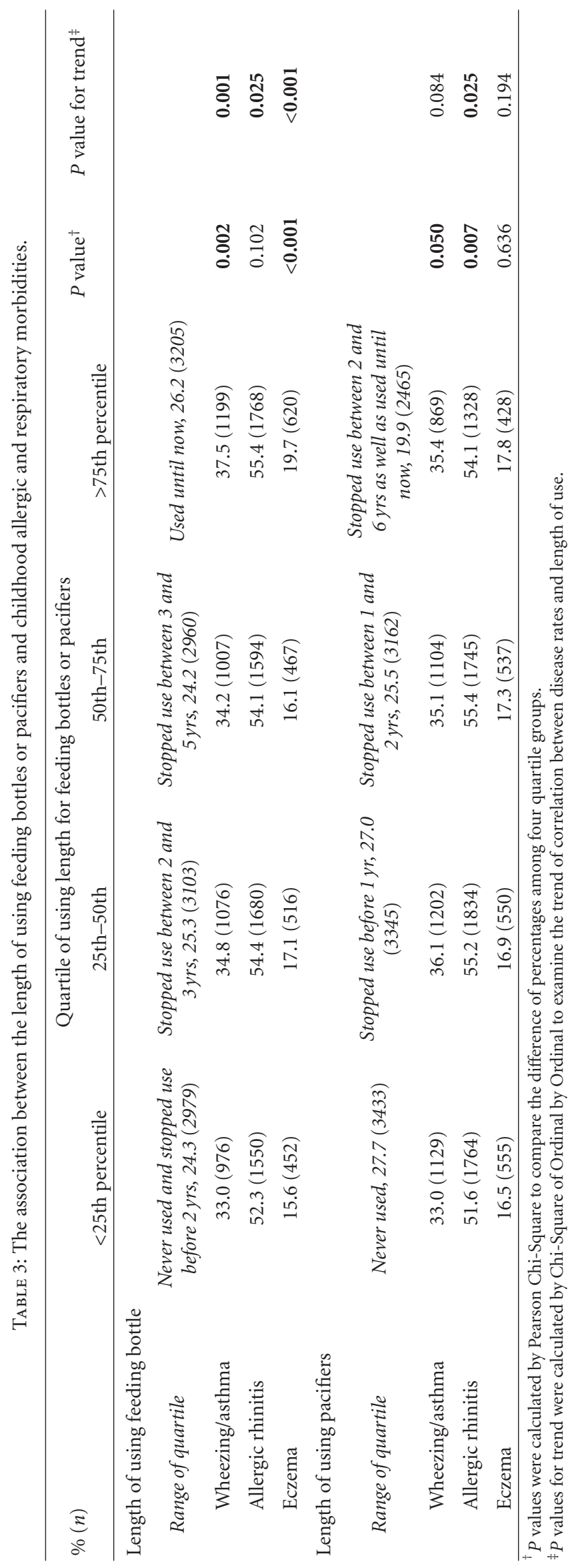


the length of using pacifiers was found for the reported symptom of allergic rhinitis ( $P$ value for trend $=0.025$ ).

The relationship between the length of use of feeding bottles and the prevalence of disease was adjusted for all confounding factors shown in Table 4. Significant effects of using feeding bottles on children's wheezing/asthma (adjusted OR: 1.05, 95\% CI 1.00-1.09), allergic rhinitis (adjusted OR: 1.04, 95\% CI 1.00-1.08), and eczema (adjusted OR: 1.07, 95\% CI 1.01-1.12) were found. The significant dose-dependent effects $(P$ value for trend $<0.05)$ between higher quartiles and the risk for having diseases or symptoms remained even after the adjustment for confounders was performed. Children who had used the feeding bottle until the time of this study (higher than the 75th percentile) were associated with a significant risk for reporting outcomes of interest compared to the first quartile (less than the 25th percentile) of subjects who had never used or stopped use before 2 years old.

\section{Discussion}

This study was the first to reveal that the use of feeding bottles among children might be one of the risk factors for the development of asthma and allergic diseases in Asian countries. Overall, we observed that a longer period of use of feeding bottles indicated a higher risk of diseases/symptoms among preschool children after adjustment for various confounders, including the children's age, gender, gestational age, birth weight, length of time being breastfed, the age first given infant formula or complementary foods, family history, parental educational levels, and smoking status, as well as the problem of indoor water damage.

Rising prevalence and morbidity of childhood asthma and allergic diseases has been observed globally $[6,7]$. Taiwan has also been facing the same challenges during the past 20 years [8-10]. Previous studies have reported that about $80-90 \%$ of patients first succumb to allergic diseases before they are 5 years old [11]. However, none of the studies on this topic has investigated the prevalence of diseases among preschool-aged children in Taiwan. This study was the first to conduct a regional survey of children with an age range between 2 and 6 years old in order to explore the potential risk factors contributing to the development or presence of asthma and allergic diseases. From the current analysis, a prevalence of eczema was found to be the highest in children younger than 3 years old and to decrease gradually as age increased. On the contrary, the most prevalent period for allergic rhinitis was at 6 to 7 years old, while for diagnosed asthma, it was at 5 years of age. The current profile of prevalence for asthma and allergic morbidity corresponded to the theory of "atopic march," used for describing the phenomenon of the progression of allergic disorders among predisposed children. Eczema (atopic dermatitis) is thought to be an "entry point" for subsequent allergic diseases, including asthma and allergic rhinitis $[12,13]$.

The issue of plastic and health has attracted enormous attention in recent years [14], and there is also a possibility that any harmful chemicals emitted from pacifiers or feeding bottles could be the causal factor associated with this rela- tionship. Only limited literature has reported relationships between childhood allergic diseases and the use of feeding bottles, pacifiers, or toys. One study from Japan indicated that the presence of asthmatic symptoms and eczema was associated with the use of latex for newborns who were less than 1 year old [15]. Another study conducted in Pakistan has shown early bottle feeding to be associated with higher total serum IgE levels in the study children [16]. Morass et al. in Austria also reported that children who had used pacifiers exhibited a higher percentage of wheezing symptoms during the previous 12 months [17]. The most interesting point is that a positive dose-dependent relationship was established by Morass et al. [17] between the frequency of boiling pacifiers and the percentage of children with wheezing or asthma. The authors tended to explain these phenomena through the "hygiene hypothesis," since boiling the pacifier less frequently might be a measure of generally lower hygiene levels, whereas boiling the pacifier daily might result in a decline in children's microbial exposure and, therefore, to increases risk of developing asthma and allergic diseases [17]. However, a study in China found that BPA was released within 24 hours from four brands of baby bottles at room temperatures of $24^{\circ} \mathrm{C}, 40^{\circ} \mathrm{C}$, and $100^{\circ} \mathrm{C}$, while increased temperatures led to higher release of BPA from the baby bottles [18]. Kubwabo et al. also showed the level of BPA from polycarbonate (PC) bottles increased with temperature and incubation time [19]. BPA has been concluded to might enhance allergic sensitization and bronchial inflammation during perinatal exposure and responsiveness in a susceptible animal model of asthma $[20,21]$. A likely potential health risk of plastic exposure through the use of feeding bottles on asthma/allergies is therefore highly speculated. On the other hand, Sugita et al. [22] reported high levels of di-2-ethylhexyl phthalate (DEHP) (average $162 \mathrm{mg} / \mathrm{g}, 2.0-380 \mathrm{mg} / \mathrm{g}$ ) in pacifiers and other related products that were used frequently by infants. Exposure to phthalates, one of most common plasticizers used in daily life, has shown its potential to be correlated with allergies and asthma in both animal and epidemiologic studies $[2,3]$. Our recent publication also revealed that levels of indoor dust-borne benzylbutyl phthalate (BBzP) and dibutyl phthalate (DBP) as well as the urinary metabolites monon-butyl phthalate (MBP) and mono-2-ethylhexyl phthalate (MEHP) are associated with increased risks of allergies and asthma after taking into account exposure to other indoor pollutants [23].

We understand that the evidence might not be strong enough, constrained by the nature of a cross-sectional study design, and the casual relationship could not be established. However, it is also evident that such a study is aimed to raise new hypotheses between emergent exposures and the outcomes of significant interest. After further adjustments of confounders, it is believed that potential health concern of using feeding bottles should be attended to in the future.

\section{Conclusions}

While people have recently had dramatically increased exposure to various emerging chemicals in large amounts, 


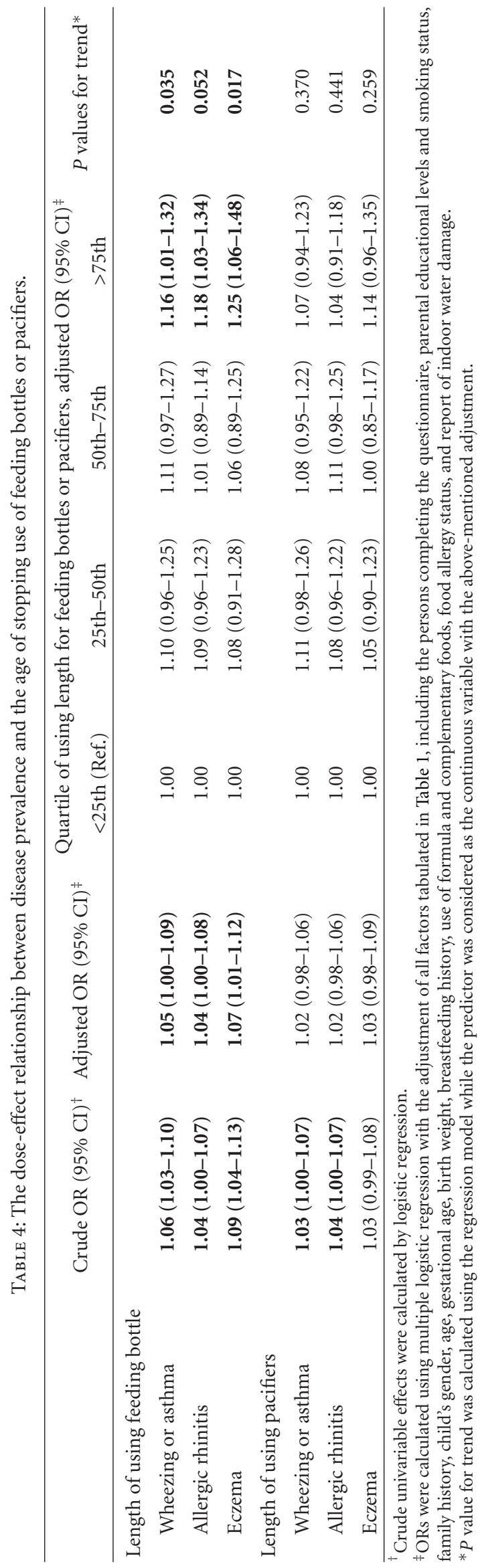


the group about which there is the most concern has been children, and the current study was the first to reveal the potential risk of using plastic consumer products, such as feeding bottles, as it was indicated from reported health status in an East Asian population. The specific underlying mechanism of feeding bottles usage resulting in the observed health outcomes warrants future investigation.

\section{Acknowledgments}

The authors are in great debt to all parents for their participation and to the in-house assistants for their most dedicated and professional contributions, including Renee $\mathrm{Wu}$, ShuYing $\mathrm{Su}$, and Wei-Ping Lin. This study was supported by a Grant from the Taiwan National Science Council, NSC 952314-B-006-019.

\section{References}

[1] T. Schettler, "Human exposure to phthalates via consumer products," International Journal of Andrology, vol. 29, no. 1, pp. 134-139, 2006.

[2] C. G. Bornehag and E. Nanberg, "Phthalate exposure and asthma in children," International Journal of Andrology, vol. 33, no. 2, pp. 333-345, 2010.

[3] I. Kimber and R. J. Dearman, "An assessment of the ability of phthalates to influence immune and allergic responses," Toxicology, vol. 271, no. 3, pp. 73-82, 2010.

[4] N. Pearce, S. Weiland, U. Keil et al., "Self-reported prevalence of asthma symptoms in children in Australia, England, Germany and New-Zealand-an international comparison using the ISAAC protocol," European Respiratory Journal, vol. 6, no. 10, pp. 1455-1461, 1993.

[5] C. G. Bornehag, J. Sundell, and T. Sigsgaard, "Dampness in buildings and health $(\mathrm{DBH})$ : report from an ongoing epidemiological investigation on the association between indoor environmental factors and health effects among children in Sweden," Indoor Air, vol. 14, no. 7, pp. 59-66, 2004.

[6] N. Pearce, N. Ait-Khaled, R. Beasley et al., "Worldwide trends in the prevalence of asthma symptoms: Phase III of the International Study of Asthma and Allergies in Childhood (ISAAC)," Thorax, vol. 62, no. 9, pp. 758-766, 2007.

[7] W. Eder, M. J. Ege, and E. Von Mutius, "The asthma epidemic," New England Journal of Medicine, vol. 355, no. 21, pp. 2226$2235,2006$.

[8] H. C. A. Tsuang, H. J. J. Su, F. F. Kao, and H. C. Shih, "Effects of changing risk factors on increasing asthma prevalence in southern Taiwan," Paediatric and Perinatal Epidemiology, vol. 17, no. 1, pp. 3-9, 2003.

[9] P. F. Liao, H. L. Sun, K. H. Lu, and K. H. Lue, "Prevalence of childhood allergic diseases in Central Taiwan over the past 15 years," Pediatrics and Neonatology, vol. 50, no. 1, pp. 18-25, 2009.

[10] Y. L. Lee, Y. C. Lin, B. F. Hwang, and Y. L. Guo, "Changing prevalence of asthma in Taiwanese adolescents: two surveys 6 years apart," Pediatric Allergy and Immunology, vol. 16, no. 2, pp. 157-164, 2005.

[11] H. Bisgaard and K. Bonnelykke, "Long-term studies of the natural history of asthma in childhood," Journal of Allergy and Clinical Immunology, vol. 126, no. 2, pp. 187-197, 2010.

[12] J. M. Spergel and A. S. Paller, "Atopic dermatitis and the atopic march," Journal of Allergy and Clinical Immunology, vol. 112, no. 6, supplement 1, pp. S118-S127, 2003.
[13] J. Ker and T. V. Hartert, "The atopic march: what's the evidence?” Annals of Allergy, Asthma \& Immunology, vol. 103, no. 4, pp. 282-289, 2009.

[14] R. U. Halden, "Plastics and health risks," Annual Review of Public Health, vol. 31, pp. 179-194, 2010.

[15] H. Kimata, "Latex allergy in infants younger than 1 year," Clinical and Experimental Allergy, vol. 34, no. 12, pp. 1910-1915, 2004.

[16] H. Satwani, A. Rehman, S. Ashraf, and A. Hassan, "Is serum total IgE levels a good predictor of allergies in children?" Journal of the Pakistan Medical Association, vol. 59, no. 10, pp. 698702, 2009.

[17] B. Morass, U. Kiechl-Kohlendorfer, and E. Horak, "The impact of early lifestyle factors on wheezing and asthma in Austrian preschool children," Acta Paediatrica, International Journal of Paediatrics, vol. 97, no. 3, pp. 337-341, 2008.

[18] X. Li, G. G. Ying, H. C. Su, X. B. Yang, and L. Wang, "Simultaneous determination and assessment of 4-nonylphenol, bisphenol A and triclosan in tap water, bottled water and baby bottles," Environment International, vol. 36, no. 6, pp. 557-562, 2010.

[19] C. Kubwabo, I. Kosarac, B. Stewart, B. R. Gauthier, K. Lalonde, and P. J. Lalonde, "Migration of bisphenol A from plastic baby bottles, baby bottle liners and reusable polycarbonate drinking bottles," Food Additives and Contaminants. Part A, vol. 26, no. 6, pp. 928-937, 2009.

[20] T. Midoro-Horiuti, R. Tiwari, C. S. Watson, and R. M. Goldblum, "Maternal bisphenol a exposure promotes the development of experimental asthma in mouse pups," Environmental Health Perspectives, vol. 118, no. 2, pp. 273-277, 2010.

[21] E. S. Kwak, A. Just, R. Whyatt, and R. L. Miller, "Phthalates, pesticides, and Bisphenol- a exposure and the development of nonoccupational asthma and allergies: how valid are the links?" The Open Allergy Journal, vol. 2, no. 45-50, 2009.

[22] T. Sugita, K. Hirayama, R. Nino, T. Ishibashi, and T. Yamada, "Contents of phthalate in polyvinyl chloride toys," Shokuhin Eiseigaku Zasshi, vol. 42, no. 1, pp. 48-55, 2001.

[23] N. Y. Hsu, C. C. Lee, J. Y. Wang et al., "Predicted risk of childhood allergy asthma, and reported symptoms using measured phthalate exposure in dust and urine," Indoor Air. In press. 


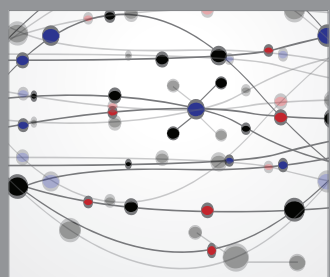

The Scientific World Journal
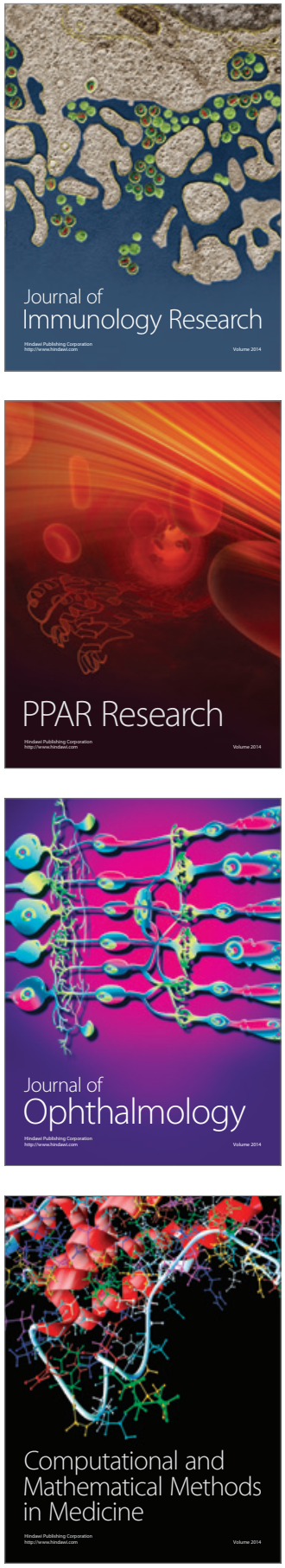

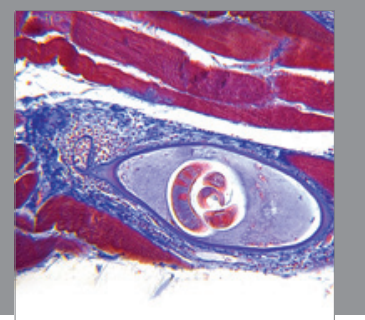

Gastroenterology

Research and Practice
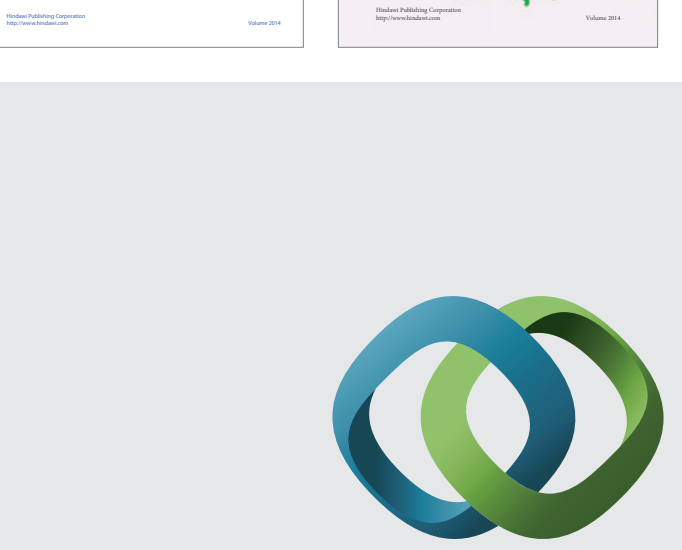

\section{Hindawi}

Submit your manuscripts at

http://www.hindawi.com
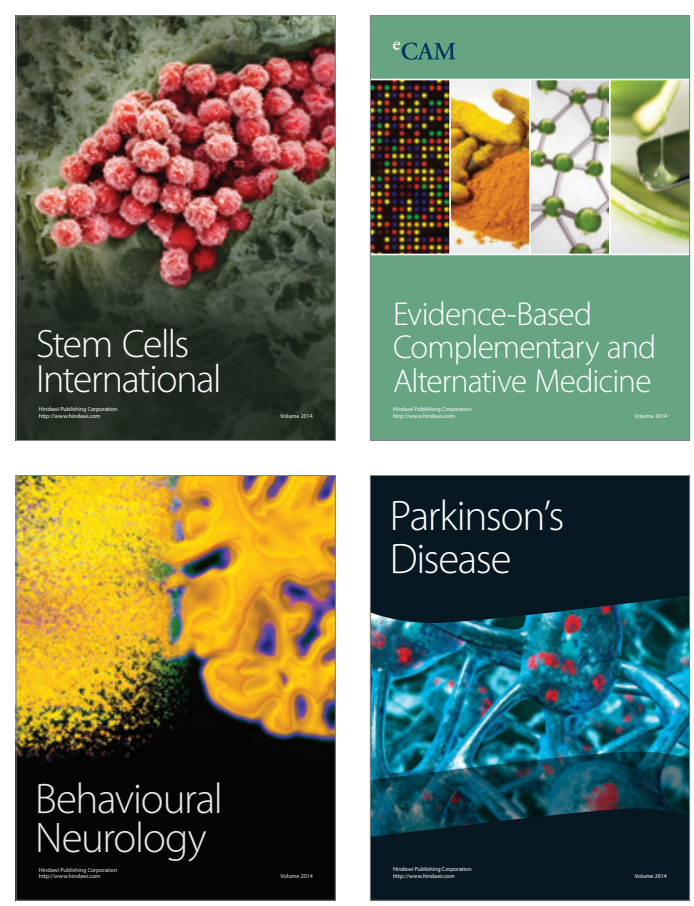

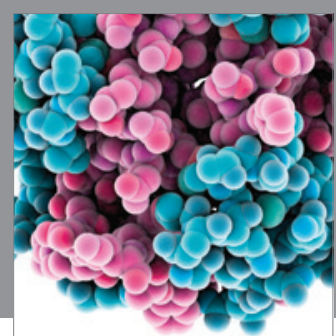

Journal of
Diabetes Research

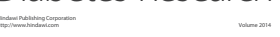

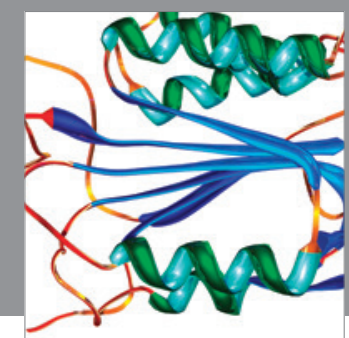

Disease Markers
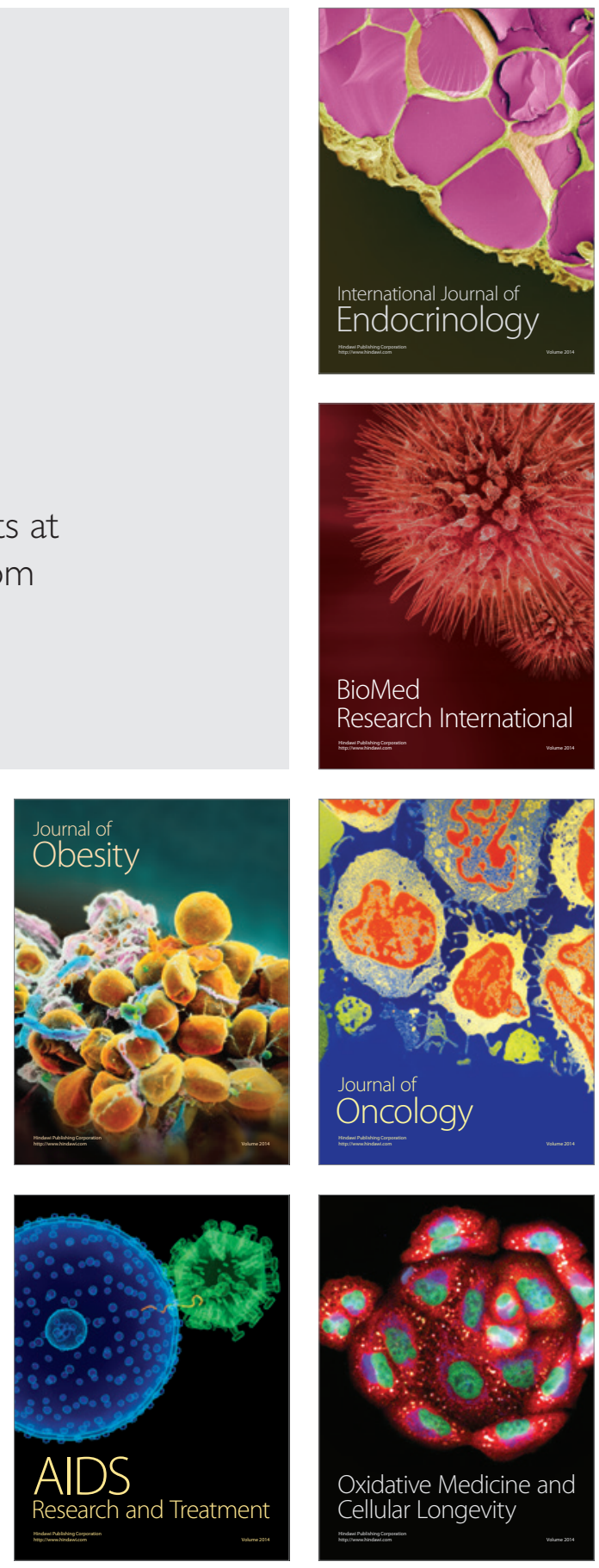